\title{
NEURAL NETWORK BASED VECTOR CONTROL OF INDUCTION MOTOR
}

\author{
Uthra.R ${ }^{1}$, N.Kalaiarasi ${ }^{2}$, P.Srinivas Aruntej ${ }^{3}$ \\ ${ }^{1}$ Department of Electrical \& Electronics, SRM University, Chennai, India \\ uthra.raktr.srmuniv.ac.in \\ ${ }^{2}$ Department of Electrical \& Electronics, SRM University, Chennai, India \\ kalaiarasi.nektr.srmuniv.ac.in \\ ${ }^{3}$ Department of Electrical \& Electronics, SRM University, Chennai, India \\ tejarun13@gmail.com
}

\begin{abstract}
Stator current drift compensation of induction motor based on RBF neural network is proposed here. In vector control of induction motor decoupling of speed and rotor flux equations and their simultaneous control are used to achieve the highest efficiency and fast dynamic performance. The highest efficiency is reached when the proper flux is selected and as a result of dynamic decoupling of speed and rotor flux equations, the rotor flux can be modified to achieve the highest efficiency and make the speed be at its desired value. The precise control of these changes can also be done using radial basis function neural network (RBFNN). Once neural network gets trained then it is able to differentiate between normal and fault conditions and therefore acts in accordance to the change that could bring back the system to normal condition. Here, neural network is used to compute the appropriate set of voltage and frequency to achieve the maximum efficiency for any value of operating torque and motor speed.
\end{abstract}

\section{KEYWORDS}

Radial Basis Function Neural Network (RBFNN), Induction Motor, Vector control, k-means algorithm.

\section{INTRODUCTION}

A drive system basically consists of an electric machine, a converter, primary sensor for feedback signal, feedback signal estimator and system controller. The sensors are extremely important in a drive system or any other feedback control system because primarily all control algorithms are based on measurements. The sensor faults cause incorrect measurement of feedback signals due to malfunction in the transducers and sensor circuit elements and upsets the system performance. This paper proposes the use of Auto Associative neural network to compensate the drift problem in feedback current sensors in a vector controlled induction motor drive.

Scalar control involves controlling only the magnitude of the control variables with no concern for the coupling effects between these variables. Conversely, vector or field orientated control involves adjusting the magnitude and phase alignment of the vector quantities of the motor. Scalar control, such as the Constant Volts/Hertz method when applied to an AC induction motor is relatively simple to implement but gives a sluggish response because of the inherent coupling effect due to torque and flux being functions of current and frequency. Vector control de-couples the vectors of field current and armature flux so that they may be controlled independently to

Sundarapandian et al. (Eds) : ACITY, AIAA, CNSA, DPPR, NeCoM, WeST, DMS, P2PTM, VLSI - 2013 pp. 75-83, 2013. (C) CS \& IT-CSCP 2013

DOI : $10.5121 /$ csit.2013.3409 
provide fast transient response [1]. Accurate position control is not possible with scalar control since this requires instantaneous control of the torque. This requires either, instantaneous change to the stator currents, which is not possible due to energy storage effects, or instantaneous change to the rotor current which in the case of scalar control is controlled indirectly via the stator currents. Similarly, whilst scalar control may provide acceptable steady state speed control, precise and responsive speed control due to load changes requires accurate and responsive torque control. The vector approach overcomes the sluggish transient response when using scalar control of AC motors [7].

\section{VECTOR CONTROL}

Vector control of an Induction motor is also called Field orientation control. In a typical AC induction motor, three alternating currents electrically displaced by $120^{\circ}$ are applied to three stationary stator coils of the motor. The resulting flux from the stator induces alternating currents in the 'squirrel cage' conductors of the rotor to create its own field these fields interact to create torque. Unlike a DC machine the rotor currents in an AC induction motor cannot be controlled directly from an external source, but are derived from the interaction between the stator field and the resultant currents induced in the rotor conductors [13].

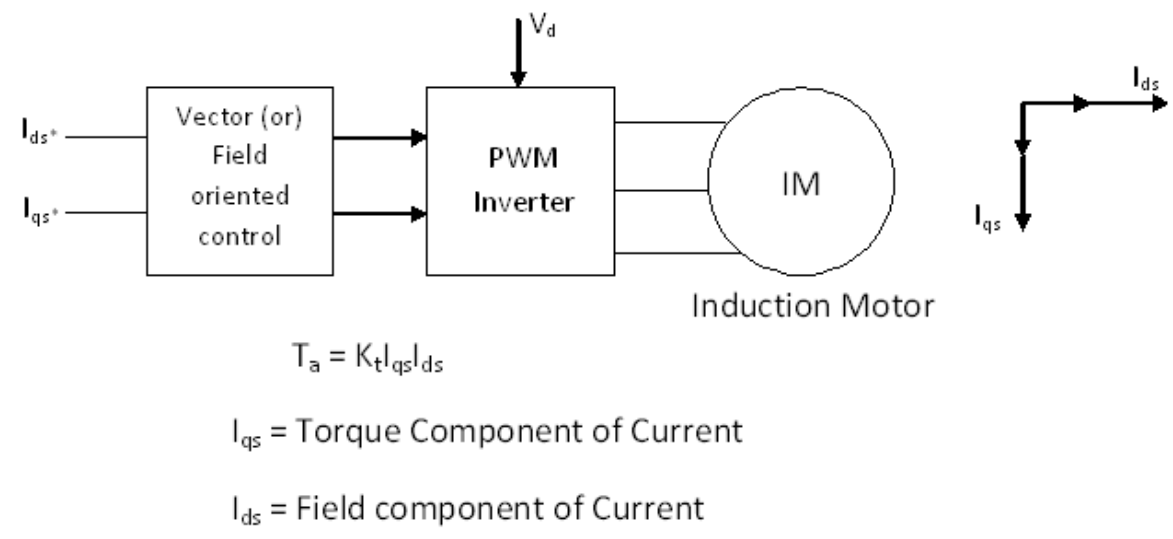

Figure 1. Vector control of Induction motor

Vector control of an AC induction motor is analogous to the control of a separately excited DC motor [7]. In a DC motor the field flux $\psi_{\mathrm{f}}$ produced by the field current $\mathrm{I}_{\mathrm{f}}$ is perpendicular to the armature flux $\psi_{\mathrm{a}}$ produced by the armature current $\mathrm{I}_{\mathrm{a}}$. These fields are decoupled and stationary with respect to each other. Therefore when the armature current is controlled to control torque the field flux remains unaffected enabling a fast transient response.

In a vector-controlled drive, the machine stator current vector $\mathrm{I}_{\mathrm{s}}$ has two components: $i_{d s}$ or flux component and $i_{q s}$ or torque component, as shown in the phasor diagram. These current components are to be controlled independently, as in a dc machine, to control the flux and torque, respectively. The $i_{d s}$ is oriented in the direction of $\psi_{\mathrm{r}}$, and $i_{q s}$ is oriented orthogonally to it. The controller should make the two inverse transformations, where the unit vector $\cos \theta_{\mathrm{e}}$ and $\sin \theta_{\mathrm{e}}$ in the controller should ensure correct alignment of $i_{d s}$ in the direction of $\psi_{\mathrm{r}}$ and $i_{q s}$ at $90^{\circ}$ ahead of it. Obviously, the unit vector is the key element for vector control [8]. There are two methods of vector control based on the derivation of the unit vector. These are the direct (or feedback) method and indirect (or feed forward) method. For closed-loop flux control in constant-torque and field weakening regions, $i_{\mathrm{ds}}$ can be controlled within the programmed flux control loop so that the inverter always operates in PWM mode [1]. 


\section{DRIVE SYSTEM}

It has been established that $i_{q}$ and $i_{d}$ of the rotating reference frame must be controlled to provide good dynamic control of the induction motor. Using closed loop control ordered quantities of $i_{q}$ and $i_{d}$ are compared with the actual values measured from the motor. In order to obtain the motor values, transformations on the measured 3 phase stator currents into the direct and quadrature components of the rotating reference frame are performed. The resulting error terms are then transformed back to 3 phase quantities and applied to the motor.

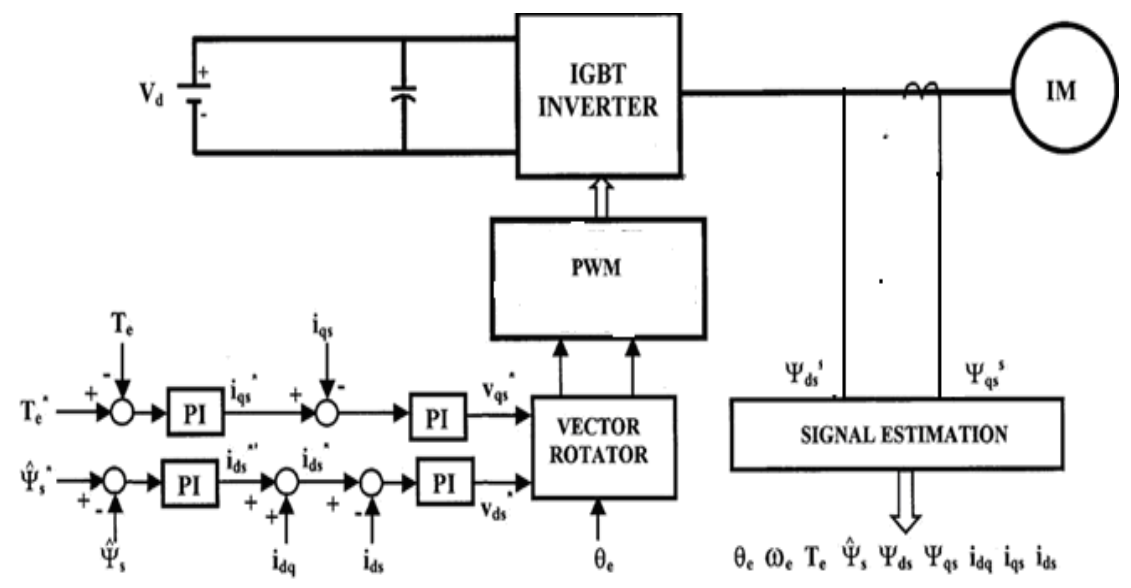

Figure 2. Block diagram of Vector control of Induction motor

The power circuit (Fig.2) consists of a DC source (battery or rectifier DC), PWM IGBT inverter and cage type induction motor. The signal processing blocks include machine phase current sensors, signals computation and controller, and the PWM algorithm [3]. The command torque $\left(\mathrm{T}_{\mathrm{e}^{*}}\right)$ and stator flux $\left(\psi_{\mathrm{s}^{*}}\right)$ generate the active $\left(\mathrm{i}_{\mathrm{gs}^{*}}\right)$ and reactive $\left(\mathrm{i}_{\mathrm{ds}^{*}}\right)$ current commands within the block which are then translated to generate input for PWM controller. The machine terminal voltages and currents are sensed and converted into stationery frame $d_{s}-q_{s}$ signals. These signals are then converted to rotating frame. The synchronous control loops then generate $\mathrm{V}_{\mathrm{q}^{*}}$ and $\mathrm{V}_{\mathrm{ds}^{*}}$ signals. $\mathrm{V}_{\mathrm{qs}^{*}}$ and $\mathrm{V}_{\mathrm{ds}^{*}}$ signals are then translated using inverse Clarke transformation and fed as input to PWM controller. The PWM controller receives signals at the input and translates to gate drive signals for the IGBT inverter [8].

\section{RAdial BaSis FunCtion NeURAL Network}

RBF is a Multilayer Perceptron Network (MLP) which is based on unit computing of non-linear function of scalar product of input \& output. For an auto associative net the training input and target output vectors are identical. A stored vector can be retrieved from distorted or partial input if the input is sufficiently similar to it. Auto-associative neural network is basically a feed forward, fully-connected, multilayer perceptron (MLP) type neural network. The general RBF network consists of 3 layers, Input layer, Hidden layer, Output layer. 


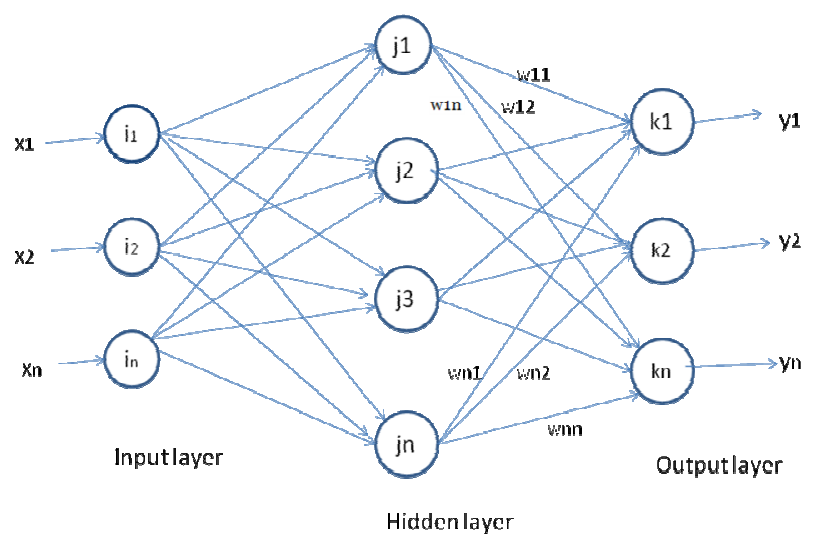

Figure 3. Architecture of RBFNN

No. of neurons in input layer $=3$

No. of neurons in hidden layer $=4$ (obtained by using k-means algorithm).

No. of neurons in output layer $=3$

The input layer is made up of source nodes that connect the network to its environment. The second layer, the only hidden layer in the network applies a non liner transformation from the input space to the hidden space. The output layer is linear, supplying the response of the network to the signal applied to the input layer.

\subsection{Algorithm}

1. First the input is given to the input layer.

2. The network is simulated and initialized. For deciding the number of neurons in hidden layer k-means algorithm is used.

3. Iterate until the network converges.

4. Calculate the error between the network's o/p \& the target o/p. if the error isn't in the desired limit go to step 3 else go to step 5 .

5. Observe the performance of the network with the training and the test data. Re-train if necessary.

\subsection{K - means Algorithm}

1. Choose initial centres $\mathrm{c}_{1}, \ldots, \mathrm{c}_{\mathrm{k}}$.

2. While the clusters are changing, repeat step 3 to 4 .

3. Assign data point $\mathrm{p}_{\mathrm{i}}$ to the cluster whose centre $\mathrm{C}$ is closest. This can be done by using Euclidean distance.

4. Update the cluster centres given by :-

$$
\mathrm{C}=(1 / \mathrm{n}) \sum \mathrm{P} \text {. }
$$

$\mathrm{n}=$ number of points in $\mathrm{C}$ 


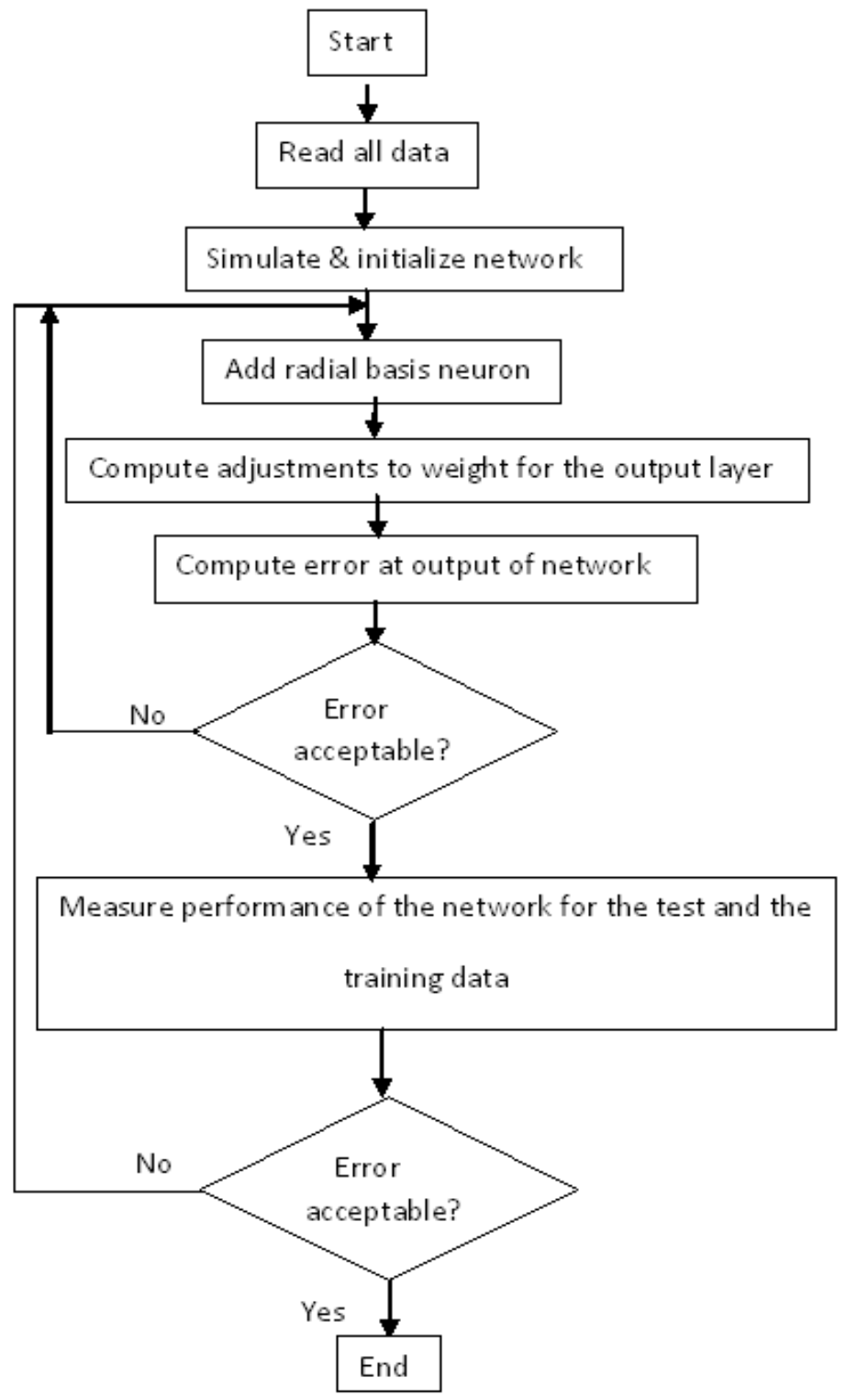

Figure 4. Flowchart of RBF neural network

\section{SimULATION STUDY}

To implement a RBF neural network for drift compensation of stator current, multiplicative errors were implicated in the stator part of the induction motor. Stator currents were observed for different values of errors implemented in $\mathrm{i}_{\mathrm{a}}, \mathrm{i}_{\mathrm{b}}, \mathrm{i}_{\mathrm{c}}, \mathrm{i}_{\mathrm{a}} \mathrm{i}_{\mathrm{b}}, \mathrm{i}_{\mathrm{b}} \mathrm{i}_{\mathrm{c}} \& \mathrm{i}_{\mathrm{c}} \mathrm{i}_{\mathrm{a}}$ ranging from 0.1 to 1 and at voltages ranging from 210 to 510 to obtain the training data for neural network. The corresponding stator currents are shown in Figure 5 and 6. By introducing different errors in Matlab Simulink, 960 sets of training data were obtained. Using this data the RBF neural network with the implementation of k-means algorithm was trained and tested. 


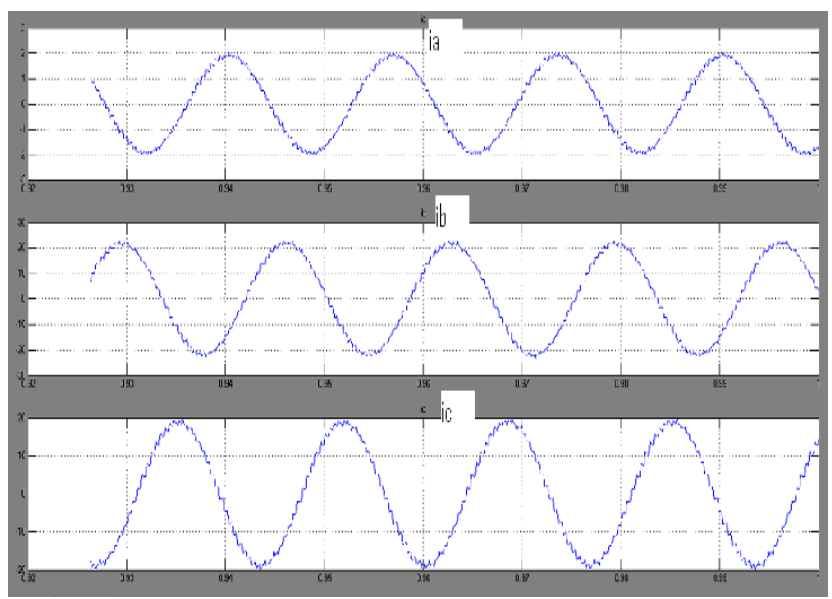

Figure. 5. Stator currents $\left(i_{a}, i_{b}, i_{c}\right)$

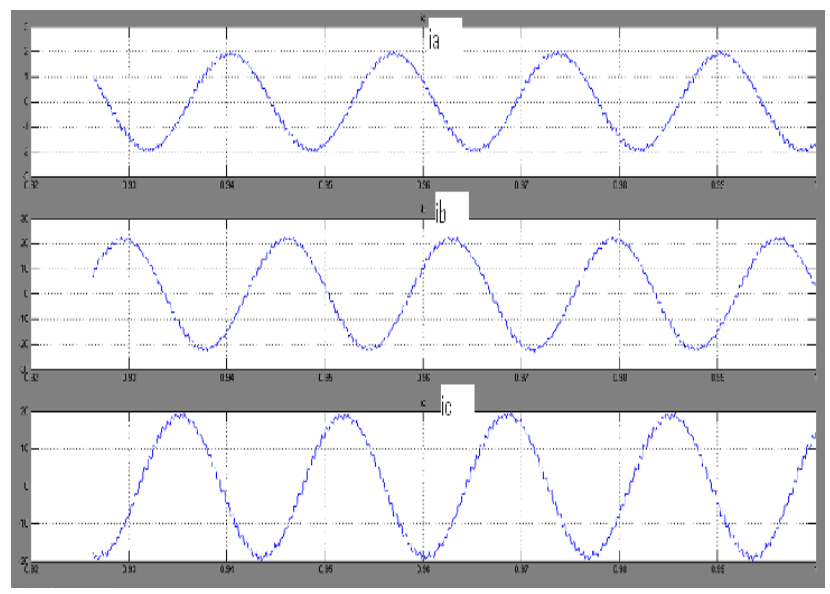

Figure.6. Stator currents with error factor 0.1 in $\mathrm{i}_{\mathrm{a}}$

\section{RESULTS}

Vector control of Induction motor was simulated using Matlab Simulink and three stator currents $\mathrm{i}_{\mathrm{a}} \mathrm{i}_{\mathrm{b}}, \mathrm{i}_{\mathrm{c}}$ were noted. Multiplicative errors were implicated in the stator currents to obtain the training data for neural network. The RBF Neural network with the implementation of k-means algorithm was trained and tested. Every time numbers of clusters and radius in the k-means algorithm were varied and the result of the k-means algorithm which gives the clusters center and the number of training data in each cluster were implemented in the RBFNN. Maximum absolute error, minimum absolute error (target- output) and root mean square error (RMSE) at different radius and cluster in the network were found to reduce. Figure 7 shows that the minimum RMSE is at 125 clusters. So for 960 sets of training data maximum absolute error was 2.006, minimum absolute error was 0.00022339 and the RMSE was 0.34525 at 125 clusters and radius 5 . The satisfactory output was obtained for the layer with neurons 3-125-3 (Input-Hidden-Output). RBF neural network with implementation of k-means algorithm was trained with 960 sets of data and satisfactory output was obtained. 


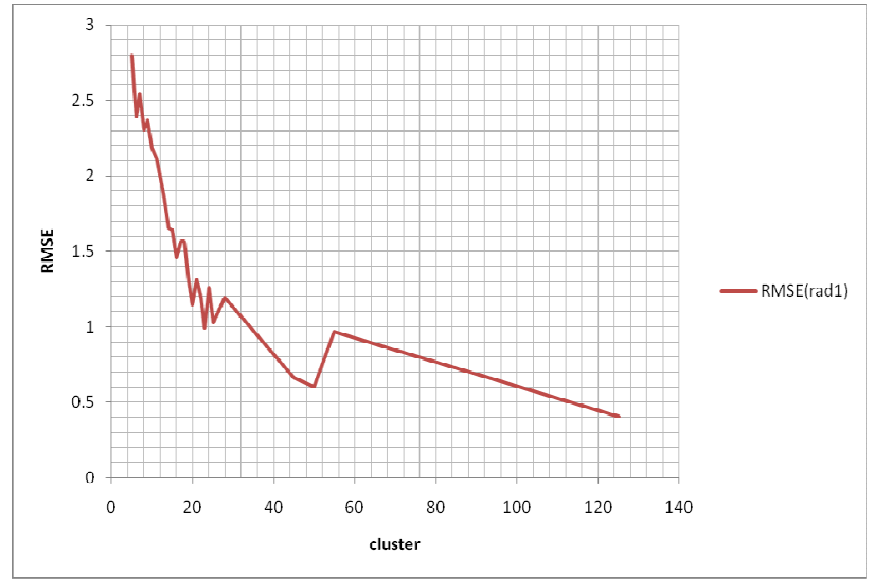

Figure. 7. Root Mean Square Error (RMSE) Vs cluster.

Table 1 Tested data with trained RBF Neural Network

\begin{tabular}{|c|c|c|c|c|c|c|c|c|}
\hline \multicolumn{3}{|c|}{ Input Stator Current } & \multicolumn{3}{|c|}{ Target Stator Current } & \multicolumn{3}{|c|}{ Output Stator Current } \\
\hline Ia & Ib & Ic & Ia & Ib & Ic & Ia & Ib & Ic \\
\hline 1.5 & 15 & 15 & 15 & 15 & 15 & 15.002 & 15.002 & 15.002 \\
\hline 15 & 13 & 15 & 15 & 15 & 15 & 14.994 & 14.994 & 14.994 \\
\hline 15 & 15 & 4.5 & 15 & 15 & 15 & 15.007 & 15.007 & 15.007 \\
\hline 6 & 17 & 17 & 17 & 17 & 17 & 17.007 & 17.007 & 17.007 \\
\hline 17 & 3.5 & 17 & 17 & 17 & 17 & 16.993 & 16.993 & 16.993 \\
\hline 17 & 17 & 8 & 17 & 17 & 17 & 16.998 & 16.998 & 16.998 \\
\hline
\end{tabular}


RBFNN was tested and the output shown in Table1 was obtained. It can be observed that the drift in stator current due to various faults in all the three phases are compensated by the neural network validating that trained neural network restores back the closest possible original value of stator current achieving the compensation in the stator current of the Induction motor.

\section{CONCLUSION}

Vector control of Induction motor using Radial basis function neural network has been implemented in this paper. The neural network was trained with 960 sets of input data and tested to obtain a satisfactory output. The result of the K-MEANS algorithm was implemented in the RBFNN and hence the stator currents were restored to its original values. In this paper, supervised learning algorithm has been adopted to train the neural network. Artificial neural network can be implemented by either using supervised network or fixed weight network or both the types of network. By implementing the above said networks, performance of Induction motor can be improved as any change in the stator current has been compensated by the trained neural network and henceforth its performance.

\section{REFERENCES}

[1] A.K.Sharma,R.A.Gupta, Laxmi Srivastava.: Performance of ANN based indirect vector control induction motor drive, Journal of theoritical and applied Information technology. IEEE trans 2007.

[2] M.H. Jokar, B. Abdi, M. Ardebili.: Vector Control of Induction Motors Using Radial Basis Function Neural Network. (2007 IEEE trans.)

[3] L.Galotto, J.O.P. Pinto, B. Ozpineci, L.C.Leite, L.E. Borges da silva,: Sensor compensation in motor drives using Kernel Regressio., IEEE International Electric Machines and drives conference,2007

[4] L. Galotto, Bimal. K. Bose, L.C. Leite, J.O.P. Pinto, L.E. Borges da silva, Germano Lambert-Torres.: Auto-Associative Neural Network based sensor drift compensation in Indirect controlled drive system. IEEE Industrial Electronics society,2007.

[5] Kamel Baddari, Tahar Aifa, Noureddine Djarfour, Jalal Ferahtia.:Application of Radial Basis Function Artificial Neural Network to seismic data inversion. Science Direct Computers \& Geoscience 35,2009(2338-2344).

[6] A. El-Antably, L. Xiaogang and R. Martin.:System simulation of fault conditions in the components of the electric drive system. IEEE journal 1993.

[7] N. Reitere, D. Roye and P. Mannevy.:Vector based investigation of induction motor drive under fault operations. IEEE 1997

[8] Kramer. M .A.:Auto-associative Neural Networks. AIChE Journal, Vol.16

[9] X.Xu, R.N.De Donker and D.W.Novotny.: A stator flux oriented induction machine drive. IEEE 1998

[10] J.O.P.Pinto, B.K.Bose, L.E.Borges.: A stator flux oriented vector controlled induction motor drive with space-vector PWM and flux vector synthesis by neural networks. IEEE trans. on Industry Applications, Vol.37,No.5, 2001

[11] J.O.P.Pinto, B.K.Bose, L.E.Borges, and M.P.Kazmierkowski.: A neural network based space vector PWM controller for voltage fed induction motor drive.IEEE trans. 2000.

[12] B.K.Bose,Ed.,Power Electronics and variable frequency drives, IEEE Press, New York, 1996.

[13] B.K.Bose., Modern Power Electronics and AC Drives, Prentice Hall, Upper Saddle River, NJ,2002 


\section{AUTHORS}

Uthra.R completed her graduation in Electrical \& Electronics from Madras University in 2002 and Masters in Power Electronics \& Drives from SRM University in 2010. Her area of interest is artificial intelligence in power Electronics \& Drives. She is currently working as Assistant Professor in SRM University.

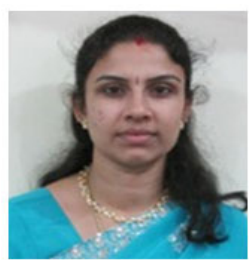

N.Kalaiarasi received the Bachelor of Engineering in Electronics and Communication Engineering from Periyar University in the year 2002 and Master of Engineering in Power Electronics and Drives from college of Engineering, Anna University in the year 2004. She is currently doing Research in the area of solar energy. She is currently working as Assistant professor (Sr.G) in the Department of Electrical and Electronics Engineering, SRM University, Chennai, India. Her area of interest includes Power Electronics, Digital Signal Processing, and Fuzzy Logic applications in Drives, solar energy.

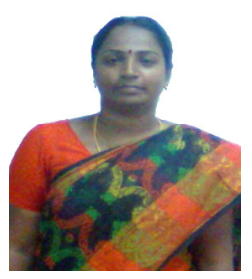

Srinivas Arun Tej $\mathrm{P}$ received the Bachelor of Engineering in Electrical and Electronics Engineering from Jawaharlal Nehru Technological University in the year 2011 and Master of Engineering in Power Electronics and Drives from SRM University in the year 2013. 